\title{
SOCIAL ATTITUDES AND VALUES OF YOUNG PEOPLE IN THE CONTEXT OF MULTICULTURAL EDUCATION
}

As a result of globalisation, more situations where pupils meet other cultures arise. Fears of unknown and also other factors contribute to the refusal of being alternate, which is expressed, in terms of human behaviour, in the form of prejudices. Educational effect of pedagogues should help eliminate these barriers among children.

Keywords: Other cultures, foreigners, attitude, prejudice, stereotypes, relationships, hostility, animosity, exclusion, inclusion, pedagogue, education, interview, argumentation, empathy, acceptance, tolerance, prosociality.

\section{Introduction}

This paper concentrates on the analysis of unfriendly, even aggressive behaviour in Slovak society, especially with regard to young people; it analyses how their attitudes are adopted and maintained and special attention is paid to the growth of a social prejudice and stereotypes and its potential rectification through teaching the young tolerance, altruism and giving them unprejudiced upbringing.

\section{Social attitudes and values as a result of social environment}

The term attitude is found in a variety of scientific disciplines and Vyrost [1] explores its explanation force. Attitudes can be defined from various points of view; most frequently as readiness for a certain action [2], which is directly connected with a decision act. Afterwards, a concrete action in a concrete situation follows [3]. Matsumoto [4] understands attitude as a reflection of evaluation of objects which occur in terms of passing thoughts or memory of an individual. The content of attitudes is determined by an individual experience of a person, social environment, but also media, social climate and public opinion. I. Ajzen and M. Fishbein [1] have attempted to explain the relationship between attitudes and behaviours (see Fig. 1):

Fishbein and Ajzen define the term attitude as emotional attraction or repulsiveness of an object for a particular person; they understand that this term represents the part of a structure which was understood as an affective part and which is closely connected with beliefs. The Fisbein and Ajzen concepts demonstrate a prevailing tendency in the field of current attitudinal research [1] with regard to noncognitive domain of personality (see Table 1). The valence of an individual or group attitude is reflected in the quality (intensity, interaction frequency) of relation; their objective diagnosis has a crucial importance for the efficacy of educational and reeducational intervention.

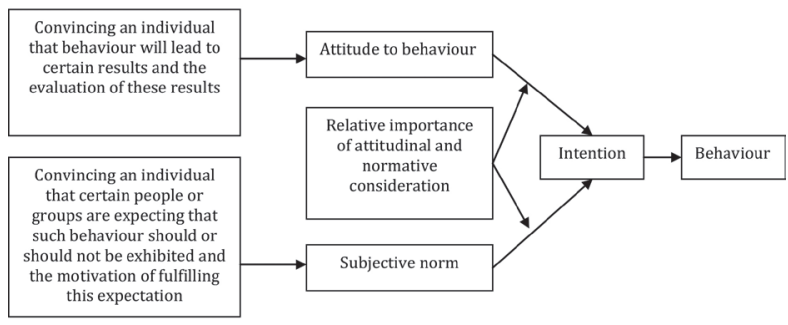

Fig. 1 Link between attitudes and behaviours [1]

A rudimentary base of attitudes is represented by a transgeneration transfer of values through the way of life in a family (for more information, see Napora) [6]. Gradually, the evaluation orientation is becoming not only a reflection of a family [7], but also the reflection of various social communities in an environment where young people can be found. Apart from this, the value system is influenced by a social origin and partial sources of stratification (education, employment, material status) as well as life style, interests (more at www.uski. sk) which determine a rather stable structure demonstrated by system of preferences in the forms of value scales. The scales are becoming more and more stable, but they undergo changes due to a consequent cognition and important life events. Maturation is typical for a rapid development of attitudes which affect

\footnotetext{
* Vlasta Cabanova

Faculty of Humanities, University of Zilina, Slovakia

E-mail: vlasta.cabanova@fhv.uniza.sk
} 
Source sphere of attitudes in the socioaffective domain of personality [5]

\begin{tabular}{|l|l|l|l|}
\hline Domain & $\begin{array}{l}\text { Cognitive domain } \\
\text { The most developed sphere of } \\
\text { school education }\end{array}$ & \multicolumn{1}{|c|}{$\begin{array}{c}\text { Noncognitive domain of personality } \\
\text { (domain neglected by school) }\end{array}$} & \multicolumn{1}{|c|}{$\begin{array}{c}\text { 3. psychomotoric } \\
\text { (domain neglected by school) }\end{array}$} \\
\cline { 3 - 4 } Representing & Brain and IQ & Feelings and EQ & motoric activity, sensory activity \\
\hline Is realized in a product & $\begin{array}{l}\text { Consciousness, containing } \\
\text { information and procedures, } \\
\text { understanding terminology, } \\
\text { argumentation }\end{array}$ & $\begin{array}{l}\text { Attitudes, preferences and values, } \\
\text { character, feelings and will } \\
\text { - gaining experiences, attitudes, } \\
\text { interpersonal relationships, } \\
\text { gradual interiorisation } \\
\text { of sociocultural values } \\
\text { and norms }\end{array}$ & skills and habits \\
Processes of education & LEVEL OF UPBRINGING & LEVEL OF TRAINING \\
\hline
\end{tabular}

nearly all spheres of life - work, learning process, having fun or interpersonal relations. M. Nakonecny [8] defines it as adopting attitudes on one's own and for oneself. Apart from this, adolescents are typical for their high variability of value preferences, which also prevails in the stage of late adolescence. Gradually, however, it is more and more stable and the importance of values regarding partner relationships and family life is growing. With regard to the values of an individual, not only features of their school institution conditions are reflected, but also the ideal profile of schools is mirrored [9]. Education which is realized in terms of traditionally organized conditions of school institutions creates only few opportunities for reflexive pedagogical situations where learners would have a chance to express their opinions, attitudes and preferences. The lack of opportunities for a closer examination of a learner's personality in an environment which contains too many tasks shows a serious deficit of a pedagogical work.

In the process of adaptation to broader societal conditions, the process itself is at first determined by a family environment; later it is also formed by an individual experience, but also by attitudes and opinions of peers, friends and idols which may display no attitudes or opinions. In this period, their lateral attitudes and opinions are expressed in the form of positive or negative contents that reflect only their momentary basic cognitive orientation and their scale of values [2]. The transparency of attitudes leads to an early detection of prejudices and other negative attitudes. The development of the value orientation depends on important life changes of adolescents (e. g. transition to university, leaving the family, partner relationship) - these may cause the changes in life philosophy and in the value orientation. The significance of family value in later adolescence is, in general, again increasing: "adolescents consider their parents to be the most influential people in their lives; they rely on their guidance with regard to solving important life questions, moral choices and setting meaningful goals. By passing their system of values on to children, the parents help them fit into society and work out their meaning of life. Moral principles of their parents represent all that is helpful for the children with regard to their orientation and finding the appropriate way" [10]. The most important values are life goals as the sources of sense of one's life and the formation of an individual as a consequence of the higher feelings presence; ethics, aesthetics and intellectual values are regarded as being the source [8]. Undergoing the process of cultivation, students consider something to be good not only if it is good for them, but when it is good for everyone in general. On the basis of higher feelings, the evaluation of stimuli in terms of the environment and concrete situations are formed. The evaluation leads to the identification or recognition of values [3]. A subjective approach towards good can be regarded as a value in the narrower, i. e. more positive sense. "The triad is formed by motives, values and meaning" In the midst of the triad, there are emotions which influence the intensity of the whole effect and evaluation process [8]. They represent the most important components in the process of value formation:

Meaning

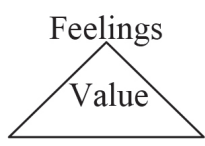

Motive

\section{Social prejudices and stereotypes and their negative effects}

Social prejudices, being considered as negative attitudes, are considered to be a frequent cause of excluding the individuals and social groups; several experts deem them to be a very important social pathogen: "prejudices strengthen social discrimination" [11] and they negatively influence the quality of life and the development of healthy interpersonal relations. Its harmful effect lies in judging people, phenomena and situations of a social life in an unobjective and unjust manner, which results in limited contact and evasive behaviour; it strengthens social prejudices even more, because being evasive due to the unknown is a natural part of a defence mechanism of the human psyche.

From the point of view of the quality of human interaction in groups, limiting the contact with a person who is linked to 
a prejudice seems to be a problem. A framework of reference is created about such people in advance. The negative thing about this is the unfavourable connotation reflected from the feelings to the subsequent behaviour. This represents negative schemes that significantly influence attitudes and behaviour. This special kind of prejudice is based on the belief which expects unfriendly or otherwise inappropriate behaviour of other person or groups of people. People with prejudice still have a memory of a situation, state, subject or a person with regard for negative connotation (concern, tension, fear) stored in their long-term memory. When one is in a contact with a person whom they have a prejudice against, it looks like as if the red light turned on and the defence mechanism is on. Thus, the behaviour of an individual is dramatically changed [12]. The prejudiced one will have a closed mind or may even begin to behave in a hostile and unfriendly way or will avoid contact.

Stereotypes represent the next barrier of an objective evaluation. Stereotypes, unlike prejudices, are not always negative (positive stereotypes also exist), to some extent they are the result of a fast modern age and a typical schematisation of people and their roles occurs. Characteristic stereotypes involve deeming countryside clean, good, but regarding a town or a city as decayed, chaotic and full of crime and sin. Stereotypes are often a part of traditions involving humour and jokes - this is a communication stereotype.

\section{Education as the support for social feelings and solidarity}

Social feelings and solidarity among people can be developed through the support of altruism (from French vie pour altrui). Altruistic behaviour is, in the context of philosophy, understood as the opposition to egoism; in the context of psychology it is perceived as the opposite of aggressive or even delinquent behaviour [13]. Altruistic behaviour can be generally understood as unselfish actions within interpersonal relations. Individuals with altruistic orientation behave in an unselfish way, have compassion for other people, their activities (thinking, feeling and performing actions) are focused on the well-being of other people in various forms (e.g. concernedness, participation, emotional support and active help). In comparison with the present, solidarity used to represent a more natural link among groups and social classes [14]. Such behaviour, in which other people are not a tool but a target of behaviour in favour of the wellbeing of other people, was introduced in terms of this theory by the father of positivism Comte as he was convinced that this feeling of an unconditional and altruistic care about the welfare of others has it righteous place in the cerebral cortex of every human being and that it is irreplaceable in society. It is an inescapable part of every human being's personality and the difference among people only lies in the range, quantity and quality, in which altruism is found with regard to various people. N. Sillamy [15] saw the roots of altruism in the defence mechanism of nature. He is of the opinion that within "beings of the same kind (even animals), one can observe spontaneous, natural and altruistic behaviour. Our brain leads us, logically, towards an altruistic behaviour, because life without altruism is not possible“. Altruism represents a higher social feeling representing a sacrifice, altruistic care, interest in problems of other people and a subsequent solution. Solidarity is a part of altruistic behaviour, understood as concord and characterized by a "strategic style of actions which, in an absolute understanding of truth, builds on giving up one's own claims in the name of helping others... It is a transcendental game based on ethic maxima" [16].

\section{Pedagogical unprejudiced effect}

School is a social institution where educators - professionals are directly expected to have a compensational effect and influence negative behaviour, harmful opinions and prejudice attitudes of pupils in a positive way from the very beginning of the school attendance. Negative attitudes become enrooted in children's mind in the early childhood through family education and a deep conviction presented by the people whom children have a close emotional relationship with and whom children undoubtedly trust - parents, members of family, acquaintances and friends. Thus, memorial experiences occur. Based on the abovementioned reason, it is difficult to behave in an unprejudiced way because every prejudice is specific - it always has a different basis and develops on the ground of reasoning, convincing and often even myths. Paradoxically, it was created on the basis of the relevant information whose core is formed by surmises or even myths with aggressive and unfriendly content. This content pretends to be a protective or a preventive one and its aim is to protect the bearer.

Within an unprejudiced effect, the effort of a pedagogue should be focused on:

- educational and reeducational influence over pupils and students who have prejudices,

- to influence disadvantaged pupils and students or persons with the threat of social exclusion on the basis of prejudices in an educational and compensation way.

Influencing the bearer of a prejudice is a complicated interactive process and it requires time for an objective diagnosis of the prejudice root and subsequent interviews with the subject (the bearer of a prejudice) with the argumentation focused on weakening the conviction. A pedagogue needs to endeavour to cast doubt on the unwavering conviction by using arguments and by logical reasoning to completely root out the prejudice. Direct bargaining is in most cases ineffective and generally, neutral or ambivalent attitude is more easily influenced than the negative one. 
Fighting against prejudices needs to be started as soon as possible; the most effective unprejudiced effect occurs in nursery schools. In terms of educational effect at primary and lower secondary school levels, one needs to start with the diagnosis of social relations with the focus on the identification of inappropriate attitudes, relationships and prejudices. Within a closer inspection, one also needs to determine which kind of prejudices people are dealing with [12]. At lower school age, the impact of an educational effect is faster because, in this period, a teacher represents an authority and idol for a pupil, they have a strong educational position and their effect on pupils is more effective than on the lower secondary school level. In this stage, space for parents and educators is opening. Within the formation of tolerance, humanity and the support of democratic feeling, the particular example of a teacher, school climate and the culture of school are important. Mutual respect, politeness and tolerance in school lead to understanding, respecting other nations and their cultures. This is a difficult task and within a normal communication, only rarely the actual cause of a negative attitude can be found.

In the higher school age, involving the cognitive domain highlights the cognitive and educational influence of a multicultural education. From the point of view of efficacy on pupils and students, it seems that solipsistic attitude is the best. The reason for this is that the greatest possible amount of students and pupils in terms of mobility are enabled to enrich their knowledge and personal experiences with other culture. Thus, they experience and understand themselves what it means to be a foreigner in other country - that being different does not necessarily mean being worse. This way of eliminating prejudices is connected with the "contact hypothesis which was formulated more than 50 years ago by G. W. Allport” [12] and [17].

In the adolescence period, which is typical for a high degree of criticality, an appropriate interpretation of relevant attitudes of popular personalities and idols provides an effective education [18]. The atmosphere of trust multiplies the effect, mainly if it is realized by a close person or authority with a high range of credit for a target subject. The most durable effect on changing the attitude of an individual has a referential group as: "the opinion of majority influences the opinion of an individual more than the opinions of experts" [11].

From the point of view of methodology, it is necessary, on the basis of the diagnostic process result, to form appropriate socioaffective goals which pay attention exclusively to procedures..." concurrently, the range of potential behaviour, which may be the foundation for affective goals, is fairly big" [19]. The strategy of pedagogical procedure of reconstruction of attitudes is, from the point of view of affective goals in terms of prejudices, realized analogically - as it is within stereotypes; it is important that the effect is even and steady regarding particular components of attitudes. The first step is to reinforce the cognitive part by the means of a new cognition (basic data, information, knowledge), suggestively, make the range of these components for the target attitude available, e. g. about uniqueness, unrepeatedness of sociocultural regulative of human behaviour, about originality of material products of human work of a particular ethnic, nationality, nation, race, other culture or about the occurrence of concrete culture specialties. When information or a fact is being processed, an individual within an emotive component of attitude searches for more meanings of their experiences, after which the strength depends on the sophistication of interaction process. Thus, the efficacy of persuasion increases through using the situation methods and taking roles; narratives enable us empathic experiencing in the context of new information and knowledge. Concerning the improvement of attitude from negative or neutral to a positive acceptance and evaluation of the high value of materialistic and spiritual culture regarding other nation, we deal with a qualitative change of value orientation and the change of preferences within a young individual, which arises from acquired conviction about a high value of national culture. Taking effective impact on both inner components into consideration, the strength of positive emotional experience of attitudes is demonstrated by conative actions such as interests, sympathy, agreement, initiative, engagement and activities. Emotionalisation represents the involvement of socioemotional sphere, the strong emotionalisation of particular information by a close person or recognized authority. It causes the fact that it is deeply-rooted in the long-term memory of an individual and by the means of a similar process, reconstruction of this attitude should be realized. Emotional argumentation has a bigger effect than the rational one.

Guided interviews require a specific preparation according to the conditions of an addressee. The main condition involves the trustworthiness of information interpreter. Effective induction - "being drawn into a problem", involving experiencing in the presence of socio-affective domain of a pupil seems to be the most effective when realized in a trustful atmosphere. Persuasion is usually less effective than open discussion (for further information, see Musil, 1999) [11].

By argumentation, the network of connections is more accessible (phenomenon, circumstances of an eventful action) in the context of yet unknown facts by which a teacher tries to cast doubt on (undermine) unscientific, unobjective conviction of a subject, who can feel uncertain or even confused in the context of new information. A pedagogue continues in creating a new perspective on a problem by adding further information and facts in a guided interview with a subject. On the basis of presented arguments, an addressee - percipient, has to make their preconcept more objective in a scientific way.

Teachers have possibilities to make changes in the following forms:

- discussions about the consequences of societal prejudices in a group or in a class,

- increasing the prestige of pupils coming from endangered minorities, 
- making pupils familiar with peculiarities of various world cultures,

- personal interviews with disadvantaged or endangered pupils and their problems,

- increasing the frequency of cooperative and interactive strategies exploitation,

- supporting the open cooperation of school with pupils' parents,

- improving the cooperation of school with pupils' families [18] and [20].

In terms of forming the consistent and unprejudiced attitudes, it is important to acquire social skills and enforcing one's personality within emotional side [21]. Strategies of a direct intervention also require the usage of educational methods of persuasion and suggestion in connection with factual argumentation [22].

\section{Conclusion}

Prejudices represent a serious barrier among healthy interpersonal relations. On the basis of the above mentioned, it follows that we cannot rely on the natural part of the feeling "other people problem perception"; this social feeling needs to be purposefully formed and developed. Similarly as being prosocial, the empathy of personality is connected with the development of emotional intelligence whose basis is built in families. School education should follow the foundation, which ought to, in terms of forming the tolerance as a personality feature and fighting the prejudices, enforce the "human proportion" - the orientation of a maturing personality on solidarity and being prosocial with regard to other people. The danger of unprofessional educational impact lies mainly in impatience or in creating pressure and this may cause the opposite, boomerang, effect.

\section{References}

[1] VYROST, J., SLAMENIK, I.: Social Psychology (in Czech). Praha : Grada, 2008. ISBN 80-24 714288.

[2] BOROS, J.: The Attitudes of Adolescents - their Characteristics, Cognition and Formation (in Slovak). Pedagogicka revue, vol. 51, No. 3, 231-239. ISSN 1335-1982.

[3] ATKINSON, R. L.: Psychology (in Czech), $2^{\text {nd }}$ edition. Praha : Portal, 2003. ISBN 80-7178-640-3.

[4] MATSUMOTO, D.: Cambridge Dictionary of Psychology. New York : Cambridge University press, 2009. ISBN 13 978-0-511-63157-3.

[5] SVEC, S.: Basic Terms in Pedagogy and Andragogy (in Slovak) - $2^{\text {nd }}$ edition. Bratislava: Iris, 2002. ISBN 80-89018-31-9.

[6] NAPORA, E.: The Communication between the Mother and the Child from the Adolescent's Point of View (in Polish). Psychologia Rozwojowa 18/1, 2013.

[7] SPISIAK, I., SPISIAKOVA, J.: Romanies (in Slovak), 1993. Available at www.uski.sk.

[8] NAKONECNY, M.: Social Psychology (in Czech) - $2^{\text {nd }}$ edition. Praha : Akademie, 2009. ISBN 978- 80-200-1679-9.

[9] DZURIAKOVA, J.: The Perception of Values - the Present and the Past (in Slovak). Acta Moralia Tyrnaviensia. Trnava : Filozoficka fakulta Trnavskej univerzity v Trnave, 2006, 78-84, ISBN 80-8082-103-8.

[10] KOLDEOVA, L., HUPKOVA, M.: The Influence of a Family on Forming the Value Orientation of Adolescents (in Slovak). Rodina na prelome tisicrocia. Bratislava : UKF Nitra, p. 221-234. 2005. Available at <http://family.sk>.

[11] MUSIL, V. J.: Special Psychology (in Czech). Olomouc : PdF UP v Olomouci, 1999. ISBN 80-244-0008-1.

[12] CABANOVA, V.: Antiprejudicial Education in the Information Society. Communications - Scientific Letters of the University of Zilina, No. 2, 2007, 46-47. ISSN 1335-4205.

[13] CAP, J.: Psychology of Education and Teaching (in Czech). Praha : UK, 1997. ISBN 80-7066-534- 3.

[14] MATOUSEK, O.: A Dictionary of Social Labour (in Czech). Praha : Portal, 2003. ISBN 80-7178-549-0.

[15] SILLAMY, N.: Psychological Dictionary (in Czech). Olomouc : Larousse UP, 2001.

[16] KABELE, J.: Rebirth - Principles of Constructions (in Czech). Praha : Karolinium, 2002. ISBN 80-7184-359-8.

[17] PRUCHA, J.: Multicultural Education (in Czech), Praha : ISV, 2001. ISBN 80-85866-72-2.

[18] CABANOVA, V.: Culture and Equalizing the Cultural Differences in School Education (in Slovak) - $2^{\text {nd }}$ edition. Presov: Metodicko-pedagogicke centrum v Presove, 74 p., 2006. ISBN 80-8045-414-0. Na pomoc ucitelom a skolam na Slovensku. Presov: ROCEPO, 2006. ISBN 80-8045-430-2. Available at http://www.mcpo.edu.sk/modules/ articles/article.php?id=46.

[19] PASCH, M. et al.: From an Educational Programme to a Lesson (in Czech). Praha : Portal, 1998, p. 51. 80-7178-127-4.

[20] KUbAlikova, A., CABANOVA, V.: The Issue of Cultural and Social Capital in the Context of Social Inequality of a Community School (in Czech). Skola v promenach: ucitel - zak - ucivo, Zlin, 2009.

[21] LELAKOVA, E.: Semantic Presentation of Emotional Processes and States Evropske pedagogicke forum 2011 Hradec Kralove: Magnanimitas, 2011, 127-133.

[22] KRALOVA, Z., METRUK, R.: Teaching and Learning Pronunciation. J. of Interdisciplinary Philology, vol. 3, No. 2, 2012 , 39-54. ISSN 1338-0591. 